МЕТОДИКА ПРЕПОДАВАНИЯ / METHODOLOGY

\title{
Инновационные подходы и технологии в туристской педагогике
}

\author{
Д.С. Тимошенко凶 \\ Воронежский государственный университет, Российская Федераџия \\ (394018, г. Воронеж, Университетская площадь, 1) \\ Поступила в редакииюю 5.11.2019 \\ Принята к публикаиии 26.02.2020
}

\begin{abstract}
Аннотация: Цель: настоящая статья посвящена изучению и обобщению особенностей реализации инновационных методов и приемов в педагогике высшей школе при подготовке специалистов сферы туризма и гостеприимства. Meтоды: диалектический метод, общелогические, теоретические и эмпирические методы. Результаты: рассматриваемые методики предлагается использовать на различных этапах образовательного процесса как самостоятельный прием, так и в сочетании с другими. На базе высшей школы предлагается создание «Лаборатории инновационных технологий в туризме и рекреационном проектировании». Bblводы: применение инновационных технологий и одновременная цифровизация туристского образования не противоречит Федеральному государственному стандарту высшего образования направления подготовки «Туризм», но, напротив, опирается на компетентностный подход Федерального стандарта в формировании базовых и профессиональных компетенций.
\end{abstract}

Ключевые слова: цифровизация туризма, инновационные технологии в туризме, практикоориентированное обучение, профессиональные компетенции в туризме, гибкие навыки, компетентностный подход, проблемное обучение, проектное обучение, интерактивные технологии, инновационная педагогика в туризме, предметно-языковое интегрированное обучение в туризме, междисциплинарность, виртуальная реальность, дополненная реальность в туризме, интернет вещей в туризме.

\section{Innovative Approaches and Technologies in Tourism Pedagogy}

\section{D.S. Timoshenko $\bowtie$}

Abstract: Purpose: This article is devoted to studying and summarising features of the implementation of innovative methods and techniques in Tourism Pedagogy. Methods: Dialectical method, logical, theoretical and empirical methods. Results: These considered techniques can be used at various stages of the educational process as a set of pedagogical tools. They can be provided as an independent method, or in combination with classical ones. The authors propose the founding of the "Laboratory of Innovative Technologies in Tourism and Recreational Design". Conclusion: The use of innovative technologies and the simultaneous digitalization of tourism pedagogy does not contradict State Federal Educational Standard in Tourism, but, on the contrary, it is based on the competency-based approach of the federal standard in the formation of essential and professional competencies of Tourism specialists.

Key words: Digitalization of tourism, innovative technologies in tourism, practice-oriented training, professional competencies, soft skills, competency-based approach, problem-based learning, project learning, interactive technology, innovative pedagogy in tourism, CLIL pedagogy in tourism, multidisciplinary, AR, VR in tourism, Internet of Things in tourism.

() Тимошенко Д.С., 2020

E-mail: artemideus@ gmail.com

(c) (i) Контент доступен под лицензией Creative Commons Attribution 4.0 License.

The content is available under Creative Commons Attribution 4.0 License. 


\section{ВВЕДЕНИЕ}

Туризм находится в тесной взаимосвязи с техническим прогрессом и инновационными технологическими решениями. Индустрия туризма и гостеприимства неразрывно связана с цифровой экономикой и одновременно процессами цифровизации педагогики. В этой связи требования, которые предъявляются сегодня к выпускникам направления туризм всех уровней (среднее профессиональное образование, бакалавриат, магистратура), высоки и должны отвечать отечественным и международным стандартам современного развития [3].

В условиях глобализации выпускник направления «туризм» всех уровней должен обладать рядом общих и профессиональных компетенций, чтобы иметь конкурентное преимущество на рынке труда. В современных условиях ценятся не только ответственные, мобильные и творческие кадры, хорошо ориентирующиеся в туристских направлениях, продукте и услугах, способных выстроить коммуникацию на иностранном языке, но все больше психологически устойчивые специалисты, способные к ежедневному и упорному профессиональному саморазвитию, обладающие высоко развитыми аналитическими способностями, склонные к проведению синтеза, выявлению закономерностей, умеющие мыслить масштабно и при этом быстро принимать решения. В понятие гибких навыков (от англ. термина «softskills»- мягкие, надпрофессиональные навыки) входит также фокусировка на задачах, скорость реакции, внимательность к мелочам и хорошая память.

Одновременно тенденции последних лет, коррелирующие с технологическим прогрессом, инновациями в информационных и мобильных технологиях, глобальной цифровизацией экономики, в том числе сферы туризма и гостеприимства, находят свое отражение и в кадровой политике туристских компаний: наряду с многофункциональными менеджерами в настоящее время растет спрос на узкопрофильных специалистов (IT, Bigdata-аналитики, Event-менеджеры, MICE-менеджеры, менеджеры медицинского туризма с медицинским образованием и др.), что особенно заметно на рынке труда в туроператорском и гостиничном секторе. Приказ Министерства образования и науки Российской Федерации «Об утверждении Федерального государственного стандарта высшего образования по направлению подготовки 43.04.02». Туризм (уровень магистратура) от 8 июня 2017 г. №5 516 четко определяет ряд компе- тенций, которым должен обладать магистр направления «туризм»: 1) способность к абстрактному мышлению, мониторингу, анализу и синтезу; 2) готовность действовать в нестандартных ситуациях и нести ответственность; 3) готовность к саморазвитию, коммуникации, самореализации; 4) способность руководить и разрабатывать новые туристские маршруты, разрабатывать стратегии развития туризма на всех уровнях.

Таким образом, роль высшего учебного заведения в образовательном процессе возрастает, а традиционные методики преподавания комбинируются с инновационными для получения наилучшего эффекта и формирования необходимых профессиональных компетенций у выпускников направлений «туризм».

Такая необходимость вызвана успешным развитием индустрии туризма и гостеприимства. Федеральный закон «Об основах туристской деятельности в Российской Федерации от 24 ноября 1996 года № 132 (с изменениями на 16 октября 2019 года)» и «Стратегия развития туризма в России до 2035 года», утвержденная Распоряжением Правительства России от 20 сентября 2019 года № 2129-p, указывают на приоритет развития туризма на территории Российской Федерации, ставят целью развивать научные исследования, создавать и реализовывать комплексные туристские проекты, развивать туристские территории специальных преференциальных режимов, содействовать формированию высококвалифицированного кадрового резерва в туризме. Поддержка туристской индустрии на законодательном уровне крайне важна, так как закон ориентирует студентов, выпускников и молодые кадры на международные профессиональные стандарты, дает возможность развиться малому бизнесу, регулирует методики передачи знаний с учетом достижений экономических, педагогических, психологических и географических наук с применением междисциплинарного подхода. Все это может служить серьезным подспорьем в вопросах формирования и продвижения качественного и конкурентоспособного туристского продукта на внутреннем и международном туристских рынках, будет способствовать повышению качества туристского обслуживания и увеличению доступности туристских услуг, отдыха и оздоровления для российских граждан и зарубежных гостей.

Необходимость полноценного и всеуровневого обеспечения индустрии туризма и гостеприимства высококвалифицированными профессиональ- 
ными кадрами определяет необходимость не только тщательного выбора средств и методов обучения, контроля качества преподаваемого материала, но и предъявляет высокие требования к профессиональным компетенциям педагогического состава, обеспечивающего профильные туристские дисциплины. К настоящему времени накоплен весомый опыт в области теории и практики туристской педагогики, разработаны отечественные методики преподавания туристских дисциплин.

\section{МАТЕРИАЛЫ И МЕТОДЫ ИССЛЕДОВАНИЯ}

Настоящее исследование посвящено разработке теоретико-методических и практических рекомендаций по применению практико-ориентированного и личностно-ориентированного подходов в туристском образовании. Рабочая гипотеза исследования состоит в совокупности теоретических положений и практических выводов, в соответствии с которыми выработка профессиональных компетенций у обучающихся по направлению «Туризм» может быть достигнута посредством комбинирования академической и практико-ориентированной междисциплинарной подготовки. К тому же с применением классических и инновационных педагогических технологий, а также через организацию научно-исследовательской работы студентов, что является существенным конкурентным преимуществом выпускников на рынке труда в сфере туризма и гостеприимства.

Теоретико-методологической основой исследования послужили концепции и гипотезы, представленные и обоснованные в классической и современной научной литературе, исследованиях, посвященных проблемам педагогики в туризме. Информационно-эмпирическая база исследования формировалась на основе нормативно-правовых и открытых информационных источников, федеральных государственных стандартов высшего и среднего профессионального образования Российской Федерации, регламентирующей документации и практических рекомендаций Всемирной туристской организации ООН (UNWTO), Европейской туристской комиссии (ЕТС), Всемирного совета по туризму и путешествиям (WTTC), материалов монографических исследований отечественных и зарубежных ученых, исследующих вопросы туристской педагогики. В исследовании применяются различные методы научного познания: диалектический метод, общелогический метод, теоретический и эмпирический методы. $\boldsymbol{H a}$ учная новизна исследования заключается в раз- работке концепции и теоретико-методическом обосновании применения инновационных педагогических технологий и реализации системного инновационного подхода в педагогике туризма.

\section{ОБСУЖДЕНИЕ РЕЗУЛЬТАТОВ}

Эффективность обучения во многом определяется применением современных инновационных обучающих методик и различных форм их реализации. Множество исследовательских работ посвящено проблемам высшей школы и профессиональной педагогики в туризме. Особенно остро вопросы компетентностного подхода и проблемной педагогики в туризме стали подниматься в периоды прохождения страны через финансово-экономические кризисы 2008 и 2014 годов. Кризисные ситуации этих лет значительно повлияли на ценовую политику как в международном, так и во внутреннем туризме. Они изменили поведение покупателей, в значительной мере затронули принципы и процессы формирования туристских пакетов и взаимных расчетов с принимающей стороной за рубежом [4]. Это, в свою очередь, нашло свое отражение в требованиях к профессиональным компетенциям кадрового резерва туристской сферы как на государственном уровне управления, так и на бизнес-предприятиях туризма, гостеприимства и смежных отраслей.

Однако высокие темпы цифровизации, которая охватывает не только сферу туризма как производственного и организационного процесса, но также и сферу туристской педагогики, требуют таких же динамичных трансформаций и от педагогических форм.

Студенты и преподаватели все активнее применяют мобильные, компьютерные, дистанционные технологии и ресурсы сети Интернет. Повсеместно и все более интенсивно внедряются новые интерактивные формы обучения, повышающие качество образования: мультимедийные лекции, деловые игры, решение ситуационных задач, диспуты-семинары [6, 7].

Ключевые общепрофессиональные компетенции магистранта направления 43.04.02 «Туризм» ФГОС ВО 3++ ОПК-1 (готовность к коммуникации в устной и письменной формах на государственном языке Российской Федерации и иностранном языке для решения задач профессиональной деятельности) и ОПК-2 (готовность руководить коллективом в сфере своей профессиональной деятельности, толерантно воспринимая социальные, этнические, конфессиональные и культур- 
ные различия) - основа дальнейших блоков профессиональной деятельности, состоящей из: 1) проектно-конструкторская деятельность (ПК-1, 2, 3); 2) производственно-технологическая деятельность (ПК-4, 5, 6); 3) организационно-управленческая деятельность (ПК-7, 8, 9); 4) сервисная деятельность (ПК-10); 5) научно-исследовательская деятельность (ПК-11, 12, 13, 14).

Магистрант направления «Туризм» должен в равной мере овладеть данными компетенциями и реализовывать их на практике как с помощью родного языка, так и языка международного общения в туризме - английского $[1,3]$.

\section{Инновационные методы педагогики туризма}

Условно методы преподавания можно разделить на традиционные и инновационные. В настоящей статье мы подробно рассмотрим инновационные. Наиболее распространенным среди инновационных технологий преподавания стал метод проектов. Он представляет собой творческое задание, где преподаватель выступает в роли консультанта-эксперта сферы туризма и гостеприимства, а студент проявляет такие качества как умение находить информацию, анализировать, редактировать, обобщать, делать выводы, составлять прогноз и как итог презентовать свое исследование с аргументированной защитой проекта. В туристской операционной деятельности метод проектов применим, например, для создания тематических карт по странам с выделением пляжей, отелей, необходимых объектов инфраструктуры (отели, туристско-информационные центры, сувенирные магазины, экскурсионные бюро, театры, рестораны, пункты проката, и т.д.). Метод проектов также применим для создания особых маршрутов по туристским тропам.

Мозговой итурм становится неотъемлемой и активно применяемой технологией на семинарских занятиях профессиональных туристских дисциплин. Он подразумевает реальную проблемную производственную ситуацию и погружение в нее студента или группы студентов. Цель применения метода - помочь студентам выработать профессиональные компетенции в условиях многозадачности, применять нестандартное мышление, быстро реагировать, расставлять приоритеты в рабочем процессе. Достигается эта цель через постановку проблемы, генерацию идей, дискуссию между сторонниками и оппонентами в процессе группирования, отбора и оценки идей. Педагог в данной ситуации выступает в роли эксперта индустрии и производства, обрабатывает и оценивает предложенные студентом или группой студентов решения. Ситуация может разворачиваться между турагентом и клиентом, администратором ресторана и гостем (группой гостей).

Проблема может быть поставлена через предложение нестандартной ситуации, в которую попадает турагент и туроператор. Студентам в качестве разминки предлагается одна из проблемных возможных ситуаций: «отказ в заселении в номер», «двойное бронирование», «банкротство туроператора», «задержка рейса», «потерянный багаж», «проезд и заселение с домашними животными». Задача студентов предложить алгоритм действий представителя туристской фирмы с целью разрешить возникшую проблему и минимизировать материальный и моральный ущерб потребителя туристского продукта (или отдельной услуги). Студентов предварительно информируют, что данная проблема должна быть решена за 10-15 минут так, чтобы репутация продавца не пострадала, а турист как можно быстрее смог получить оплаченный продукт и услугу. Группа делится на мини-группы по 3-4 человека, каждая из которых должна выработать как можно больше идей. Лидеры минигрупп отбирают лучшие варианты решений. Идеи могут быть стандартными и необычными (например, предложить систему глэмпинга в качестве компенсации за отказ в заселении в отель). Затем преподаватель-эксперт дает оценку предложенным решениям и обосновывает вероятные алгоритмы развития дальнейших событий.

Как показала практика, на занятиях по выработке профессиональных компетенций эффективным является также обучение в формате деловой uгры. Основная задача игры - развитие и закрепление ранее полученных знаний, умений и навыков самостоятельной работы, организации групповой, коллективной деятельности. В туристской сфере применима деловая игра, которая позволит студенту примерить на себя роль гида-экскурсовода, турагента или туроператора, администратора или директора гостиницы, ресторана, транспортного агентства. В процессе этой деловой игры происходит активный обмен творческими и нестандартными идеями, которые помогут расширить кругозор. Игра может носить не только проблему характера «клиент - менеджер», но и студенты имеют возможность проработать крупный проект, такой как «развитие туристской сферы в населенном пункте - регионе - стране», проецируя на себя роль управленца сферы туризма. В ре- 
зультате выпускник может наиболее конкретно определиться со своими предпочтениями на рынке труда [1].

Примером может служить игра на тему «Визовые формальности». Студенты делятся на две равные группы. Первая группа должна описать процедуру оказания визовой поддержки иностранным гражданам и для въезда на территорию Российской Федерации с туристскими целями. Вторая группа характеризует особенности оформления и подачи документов на визу в страны шенгенского соглашения. Обучающиеся должны ответить на ряд вопросов, при этом оценивается полнота, скорость, точность ответа. Примерный перечень вопросов.

1. Назовите виды приглашений для туристической поездки.

2. Перечислите данные о туристе, которые включаются в анкету для получения визы.

3. Объясните, каким образом оформляется групповая виза?

4. Обозначьте сроки действия визы и пребывания туристов.

5. Разъясните основную цель и задачи визовых центров в регионах страны.

6. Укажите, при каких случаях консульство может отказать в выдаче визы.

7. Объясните, где иностранный турист может получить туристский ваучер.

Вопросы составляются в большом объеме, чтобы полностью раскрыть тематику игры, сделать выводы об усвояемости учебного материала. Команда, которая выигрывает, получает поощрение и может предложить тему для следующей игры.

Подобные игровые методики наиболее эффективно реализуются на уровнях среднего профессионального образования и бакалавриата. Однако адаптированная игровая форма реальной производственной ситуации также вызывает интерес у магистрантов, студентов курсов повышения квалификации, а также обучающихся по программам второго высшего образования. В подобном случае игровые методики подбираются в соответствии с компетенциями слушателей курса, их профессиональной подготовки, истории путешествий и личных предпочтений.

Постепенно в процесс образовательной деятельности входит бально-рейтинговая система оценки знаний студентов. Эта технология оценивания представляет собой совокупность мероприятий, направленных на систематический контроль, своевременную корректировку, профориентацию и стимулирование самостоятельной и групповой деятельности студентов. Основным достоинством метода является дисциплинирование студентов, возможность организовать не только групповую, но и индивидуальную работу, обеспечивая учебно-методическими материалами. Оценивание и поддержание стабильной работы происходит путем стимулирования баллами. Так, любой студент может подсчитать и оценить свои возможности, повысить успеваемость до желаемой оценки. В дальнейшем в работе на производстве выпускник столкнется с бально-рейтинговой системой, где каждое достижение будет приносить ему преимущество перед коллегами. В организационной и управленческой системе туристской фирмы активно используется данный метод контроля и поощрения сотрудников. Примером может служить сезонная аттестация, которая обычно проходит в тестово-оценочной форме. В результате приобретения определенного балла, агентство не только подтверждает квалификацию, но и имеет возможно заработать дополнительный бонус: оплата рекламного пакета от курирующего оператора, информационный или ознакомительный тур (fam-trip), повышение квалификации в вузе, бесплатный дистанционный курс обучения, онлайн-тренинг.

Интерактивные и видео технологии. Они необходимы для разгрузки лекционного материала и переключения внимания студентов. Использование данной технологии в вузе помогает установить связь студент - преподаватель, а последний имеет возможность оценить уровень усвоения и провести контроль полученных студентом знаний. Оценка и контроль знаний проводится путем онлайнтестирования или выполнения системы заданий по разделу. Помимо очевидной наглядности и иллюстративности, данная методика активизирует самостоятельность студентов, дает возможность наиболее быстро и качественно усвоить информацию. Для студентов с профилем подготовки «Туризм» данная технология особенно важна. Аудирование и просмотр сюжетных видеороликов на занятиях иностранного языка профессионального общения дает возможность услышать правильно поставленную речь, научиться понимать собеседника и правильно строить диалог посредством профессиональной коммуникации. Видеоролики содержат наглядный материал о климатических особенностях дестинаций, состоянии объектов туристской инфраструктуры, дают возможность студентам ознакомиться с технологией продаж и особенностями обслуживания на всех этапах производственного процесса в туризме и гостеприимстве разных стран. 
Повысить уровень мотивации к изучению иностранного языка и овладению профессиональными компетенциями в рамках всеуровневой подготовки специалистов сферы туризма может применение технологий Content Language Integrated Learning (CLIL), предметно-языкового интегрированного обучения. Термин CLIL впервые был введен Дэвидом Маршем (David Marsh) в 1994 году. Двуединая цель, которую преследует данный метод, обеспечивает комплексность одновременного развития профессиональных навыков в туристской сфере и успешного и динамичного освоения коммуникативной компетенции с использованием как родного, а также первого и второго языка профессионального общения [3, 5]. Студенты успешно достигают двуединую цель этого подхода - повышают уровень профессиональных знаний в рамках отдельных дисциплин и одновременно развивают коммуникативные компетенции. Междисциплинарность данного подхода дает возможность приблизить обучающихся к реальной производственной ситуации при дальнейшем трудоустройстве на предприятиях туризма и гостеприимства.

Метод «Резюме» подходит для заключительных курсов направления «Туризм» и становится одним из важнейших методов обучения перед выходом на рынок труда. В условиях высокой конкуренции студент должен уметь определять, четко формулировать и презентовать свои профессиональные достоинства. Большим плюсом этого метода является практическое применение навыка общения с будущим работодателем, возможность посмотреть на свои характеристики со стороны, оценить свои возможности в сфере туризма и гостеприимства.

Разработка, адаптация, внедрение в педагогическую деятельность и использование инновационных технологий в туризме крайне необходима. К новейшим методам и формам подачи материала можно сегодня отнести: 1) глобальный комплекс e-learning (включающий электронные образовательные платформы, модули и курсы дистанционного обучения); 2) использование социальных сетей; 3) использование кроссплатформенных приложений по мгновенному обмену сообщениями; 4) использование конференц-связи, телемоста, online или off-line видео трансляции; 5) использование облачных хранилищ; 6) использование облачных вопросно-ответных систем и программных клиентов; 7) подкасты, обучающие каналы, видеохостинги; 8) мобильные приложения: разработка уникальных обучающих кроссплатформенных приложений; интеграция уже разработанных курсов, размещенных на образовательных порталах в мобильную среду; 9) применение симуляторов; 10) развитие технологий и сферы применения искусственного интеллекта; 11) работа с виртуальными ассистентами; 12) использование кроссплатформенных, мобильных и игровых приложений; 13) применение технологий 5.0.

Предметом отдельного исследования могут стать инновационные технологии обучения туристским дисциплинам в среде VR (virtualreality, виртуальная реальность) с помощью инновационных технических средств таких как беспроводная гарнитура для смартфонов, очки VR, и другие устройства, создающие виртуальную реальность и поддерживающие AR (augmentedreality, дополненная реальность - технологии, которые дополняют реальность виртуальными элементами) [5]. Данные технологии могут существенно повысить осведомленность студентов о туристских объектах, дестинациях, туристском потенциале стран и регионов.

Среда дополненной реальности направлена на повышение качества туристского образования через специально разработанное программное обеспечение, а также может применяться в области дистанционного потребления туристских и экскурсионных услуг. Применение данной технологии коррелирует с мировыми трендами цифровизации промышленных, экономических и инновационных процессов. К проблемам применения инновационных технологий дополненной и/или виртуальной реальности (AR, VR) в образовательном процессе можно отнести следующие: 1) высокая стоимость оборудования; 2) быстрое моральное и техническое устаревание аппаратуры, что вызвано высокими темпами технического развития; 3) длительный срок разработки уникального программного обеспечения; 4) дороговизна программного обеспечения.

Перспективным направлением в инновационной туристской педагогике является обучение студентов технологиям IoT (Internet of things - (размещение сенсоров на объектах, подключенных к Интернет и связаны с пользователем через мобильные приложения), а также обучение созданию виртуальных туров и участие в цифровизации и/или оцифровке туристских объектов.

К перечню стандартного инструментария, который позволяет существенно сократить время педагога на подготовку к занятиям по туристским 
Преимущества и недостатки применения инновационных технологий в образовательном процессе [1]

[Table. Advantages and disadvantages of using innovative technologies in the educational process [1]]

\begin{tabular}{|l|l|}
\hline \multicolumn{1}{|c|}{ Преимущества [Advantages] } & \multicolumn{1}{|c|}{ Недостатки [Disadvantages] } \\
\hline $\begin{array}{l}\text { Максимальное приспособление учащихся к } \\
\text { учебному процессу }\end{array}$ & $\begin{array}{l}\text { Снижение роли преподавателя, и как } \\
\text { следствие статуса значимости }\end{array}$ \\
\hline Оценка собственных умений и потенциала & $\begin{array}{l}\text { Субъективизм: оценка собственных } \\
\text { возможностей не всегда соответствует } \\
\text { действительности }\end{array}$ \\
\hline $\begin{array}{l}\text { Наглядность, иллюстративность, } \\
\text { визуализация объектов }\end{array}$ & $\begin{array}{l}\text { Избыток средств обучения приводит к } \\
\text { рассеянности внимания и снижает } \\
\text { мотивацию к самообучению }\end{array}$ \\
\hline Четкие критерии оценивания & $\begin{array}{l}\text { Теряется индивидуальный подход к } \\
\text { обучающимся }\end{array}$ \\
\hline $\begin{array}{l}\text { Возможность постоянного контроля и } \\
\text { самоконтроля усвояемых знаний }\end{array}$ & $\begin{array}{l}\text { Высокая нагрузка для самостоятельной } \\
\text { работы }\end{array}$ \\
\hline $\begin{array}{l}\text { Доступ к международным } \\
\text { образовательным ресурсам и } \\
\text { актуализированному контенту }\end{array}$ & $\begin{array}{l}\text { Низкое качество контента источников } \\
\text { глобальной сети }\end{array}$ \\
\hline $\begin{array}{l}\text { Проработка проблемных ситуаций } \\
\text { помогает не допустить ошибки в будущем }\end{array}$ & \\
\hline $\begin{array}{l}\text { Развитие коммуникативных навыков, } \\
\text { умение работать в коллективе, слушать }\end{array}$ & \\
\hline
\end{tabular}

дисциплинам, можно отнести следующие технические средства: 1) интерактивные доски для оперативной навигации по контенту профильных туристских сайтов, наглядной демонстрации процессов проектирования и моделирования в туризме; 2) обучающие версии профессионального программного обеспечения от разработчиков; устройства для видео и конференц-связи с представителями туристских компаний, обеспечения коммуникации с потенциальными работодателями, а также вузами-партнерами с целью развития коммуникативных навыков у студентов, в том числе на иностранном языке профессионального общения.

Применение вышеупомянутых инновационных педагогических технологий и инструментария изменяет роль самого учебного процесса в преподавании туристских дисциплин в вузе. Студент получает возможность наиболее широко, емко и быстро усвоить необходимый материал, научиться творчески мыслить, находить выход из проблемной ситуации, перестраиваться под быстро изменяющиеся условия. Преподавателю отводится роль координатора и консультанта, который максимизирует самостоятельность и активность студентов, помогая выработать профессиональные компетенции у обучающихся по программе «Туризм», повысить уровень конкурентоспособности будущих выпускников [2, 8].

\section{ЗАКЛЮЧЕНИЕ}

Таким образом, сформировались как положительные, так и отрицательные стороны использования инновационных технологий (таблица).

Как показывает практика, магистранты направления «Туризм» охотнее и эффективнее овладевают профессиональными навыками после практического ознакомления с проектной, туроператорской, выставочной и конгрессной деятельностью (производственная практика, временное трудоустройство, работа на стендах международных выставок и ярмарок, посещение международных мастер-классов и тренингов, привлечение к организации международных конференций и семинаров). Подобные практики дают понимание реальных должностных обязанностей на производстве, что, в свою очередь влияет на мотивацию магистрантов в вопросе профессиональной конкурентоспособности и самореализации $[1,5]$.

Для повышения эффективности процесса обучения и решения основных проблем формирования иноязычной коммуникативной компетенции у магистрантов направления «Туризм» высшей школы необходимо переосмыслить формат подачи материала и обратить особое внимание на культуру преподавания, обеспечив непрерывное самообразование и повышение квалификации педагогов туризма [3]. Стоит также отметить, что следует 
создавать возможности для интеграции инновационных технологий при организации занятий как в рамках отдельных дисциплин, так и при изучении комплексного учебного модуля.

Опыт ведущих отечественных и зарубежных вузов, осуществляющих подготовку специалистов направлений «Туризм», «Гостиничное дело», «Сервис» показывает, что институт туристских лабораторий при профильных факультетах оптимизирует и повышает качество образовательного процесса. Так, например, «Лаборатория инновационных технологий в туризме и рекреационном проектировании» может стать структурным подразделением факультета географии, геоэкологии и туризма Воронежского государственного университета и нести функцию оказания помощи и содействия руководству университета, профессорскопреподавательскому составу, а также студентам уровней среднего профессионального образования, бакалавриата, магистратуры в выполнении стоящих перед ними задач, а именно: в проведении всех видов лабораторной, практической, дисциплинарной и междисциплинарной подготовки и научно-исследовательской работы обучающихся по направлению подготовки «Туризм». Основными целями лаборатории туризма могут являться: 1) закрепление и углубление теоретических знаний по профильным дисциплинам; 2) изучение и отработка конкретного производственного процесca; 3) закрепление практических навыков и компетенций, а также опыта самостоятельной деятельности; 4) приобретение необходимых практических навыков для выполнения выпускной квалификационной работы (дипломной работы, бакалаврской работы, магистерской диссертации); 5) закрепление профессиональных компетенций учащихся в соответствии с ФГОС $3++$, а в последующем - с наиболее актуальными образовательными стандартами; 6) повышение культуры туристского потребления и популяризация принципов устойчивого развития туризма.

Подобные лаборатории туризма позволяют более полно раскрывать способности обучающихся, решать проблему низкой мотивации студентов, обеспечивают междисциплинарность практикоориентированного обучения, снижают нагрузку на педагогический состав, помогают организовать учебное время более рационально и наиболее эффективно закрепляют профессиональные компетенции учащихся, в соответствии с актуальными требованиями рынка труда сферы туризма и гостеприимства.

\section{СПИСОК ЛИТЕРАТУРЫ}

1. Тимошенко Д. С., Немчина К. В. Инновационные педагогические технологии в преподавании туристских дисциплин в вузе // Материалы II Всероссийской научно-практической конференции с международным участием «Методические вопросы и инновационные технологии в преподавании географии, туризма и естественно-научных дисциплин в вузе и школе». Воронеж, 2019, c. 196-201.

2. Тимошенко Д.С. Проблемы развития туристского рынка Российской Федерации и подготовки профессионально ориентированных кадров сферы туризма в период мирового финансово-экономического кризиса // Вестник Российского Нового Университета. Серия: Человек и общество, 2009, № 3, с. 125-130.

3. Тимошенко Д. С. Проблемы формирования иноязычной коммуникативной компетенции у магистрантов направления «Туризм». Материалы IV Международной научной конференции «Донецкие чтения 2019: образование, наука, инновации, культура и вызовы современности». Донецк, 2019, т. 4, ч. 1, с. 221-223.

4. Тимошенко Д. С., Епринцев С. А. Социально-экономические и экологические факторы, определяющие развитие и продвижение туристского потенциала Краснодарского края // Вестник Воронежского государственного университета. Серия География. Геоэкология, 2019, № 4, с. 43-48.

5. Тимошенко Д. С. Технологии формирования иноязычной коммуникативной компетенции конкурентоспособного специалиста в сфере туризма. Материалы международной научно-практической конференции «Инновационные технологии обучения иностранному языку в вузе и школе: реализация современных ФГОС». Воронеж, 2019, с. 349-356.

6. Федотов В.И., Куролап С.А. Инновационное в эколого-географическом образовании // Вестник Воронежского государственного университета. Серия География. Геоэкология, 2011, № 1, с. 188-191.

7. Федотов В. И., Куролап С. А. Современная модель университетского экологического образования // Вестник Воронежского государственного университета. Проблемы высшего образования, 2017, № 3, с. 14-18.

8. Щербакова М. В., Чайка Е. Ю. Электронное обучение как инструмент развития содержания профессиональной подготовки в вузе // Вестник Воронежского государственного университета. Проблемы высшего образования, 2016, № 4, с. 89-93.

\section{REFERENCES}

1. Timoshenko D. S., Nemchina K. V. [Innovative pedagogical technologies in travel and tourism teaching at higher school]. Materialy II Vserossiyskoy nauchno-prakticheskoy konferentsii s mezhdunarodnym uchastiyem "Metodicheskiye voprosy $i$ innovatsionnyye tekhnologii v prepodavanii geografii, turizma i yestestvenno-nauchnykh distsiplin v vuze i shkole" [Proc. Int. sci. conf. "Methodological issues and innovative technologies in the teaching of 
geography, tourism and natural sciences in high school and comprehensive school"]. Voronezh, 2019, pp. 196-201 (In Russ.)

2. Timoshenko D.S. Problemy razvitiya turistskogo rynka Rossiyskoy Federatsiii podgotovki professional'nooriyentirovannykh kadrov sfery turizma $\mathrm{v}$ period mirovogo finansovo-ekonomicheskogo krizisa [Russian tourism market challenges and tourism education development in the period of the global financial and economic crisis]. Vestnik Rossiyskogo Novogo Universiteta. Seriya: Chelovek i obshchestvo, 2009, no. 3, pp. 125-130. (In Russ.)

3. Timoshenko D.S. [Challenges of communicative competence formation in the foreign language among "Tourism" undergraduates]. Materialy IV Mezhdunarodnoy nauchnoy konferentsii "Donetskiye chteniya 2019: obrazovaniye, nauka, innovatsii, kul'tura i vyzovy sovremennosti” [Proc. Int. sci. conf. "Donetsk Readings 2019: Education, Science, Innovation, Culture and Challenges of the Present"]. Donetsk, 2019, v. 4, part 1. pp. 221-223. (In Russ.)

4. Timoshenko D. S., Yeprintsev S. A. Sotsial'no-ekonomicheskiye i ekologicheskiye faktory, opredelyayushchiye razvitiye i prodvizheniye turistskogo potentsiala Krasnodarskogo kraya. [Socio-economic and environmental factors that determine the development and promotion of the Krasnodar Region tourism potential]. Vestnik Voronezhskogo gosudarstvennogo universiteta. Ser. Geografiya. Geoekologiya, 2019, no. 4, pp. 43-48. (In Russ.)

\section{КОНФЛИКТ ИНТЕРЕСОВ}

Автор декларирует отсутствие явных и потенциальных конфликтов интересов, связанных с публикацией настоящей статьи.

Тимошенко Диана Сергеевна

кандидат экономических наук, доцент кафедры рекреационной географии, страноведения и туризма, Воронежского государственного университета, г. Воронеж, Российская Федерация,

ORCID: https://orcid.org/0000-0002-2780-6464, e-mail: artemideus@gmail.com
5. Timoshenko D.S. [Technologies for the formation of a foreign language communicative competence of a competitive tourism specialist]. Materialy mezhdunarodnoy nauchno-prakticheskoy konferentsii "Innovatsionnyye tekhnologii obucheniya inostrannomu yazyku v vuze I shkole: realizatsiya sovremennykh FGOS" [Proc. Int. sci. conf. "Innovative technologies of teaching a foreign language at a university and school: implementation of modern federal standarts"]. Voronezh, 2019, pp. 349-356. (In Russ.)

6. Fedotov V. I., Kurolap S. A. Innovatsionnoye v ekologo-geograficheskom obrazovanii [Innovation in environmental and geographical education]. Vestnik Voronezhskogo gosudarstvennogo universiteta. Ser. Geografiya. Geoekologiya, 2011, no. 1, pp. 188-191. (In Russ.)

7. Fedotov V.I., Kurolap S. A. Sovremennaya model' universitetskogo ekologicheskogo obrazovaniya [The modern model of higher environmental education]. Vestnik Voronezhskogo gosudarstvennogo universiteta. Problemy vysshego obrazovaniya, 2017, no. 3, pp. 14-18. (In Russ.)

8. Shcherbakova M. V., Chayka E. Yu. Elektronnoye obucheniye kak instrument razvitiya soderzhaniya professional'noy podgotovki $\mathrm{v}$ vuze [E-learning as a tool for the content developing of vocational training in a higher educational institution]. Vestnik Voronezhskogo gosudarstvennogo universiteta. Problemy vysshego obrazovaniya, 2016, no. 4, pp. 89-93. (In Russ.)

\section{CONFLICT OF INTEREST}

The author declares no information of obvious and potential conflicts of interest related to the publication of this article.

Diana S. Timoshenko

Cand. Sci. (Econ.), Assoc. Prof. at Department of Recreational Geography, Regional Geography and Tourism, Voronezh State University, Voronezh, Russian Federation, ORCID: https://orcid.org/0000-0002-2780-6464, e-mail: artemideus@gmail.com 